\title{
Vulnerability and adaptation of European farmers: a multi-level analysis of yield and income responses to climate variability
}

\author{
Pytrik Reidsma · Frank Ewert · Alfons Oude Lansink • \\ Rik Leemans
}

Received: 14 November 2007 / Accepted: 30 July 2008/Published online: 9 September 2008

(C) The Author(s) 2008. This article is published with open access at Springerlink.com

\begin{abstract}
Climate change will affect crop yields and consequently farmers' income. The underlying relationships are not well understood, particularly the importance of crop management and related factors at the farm and regional level. We analyze the impacts of trends and variability in climatic conditions from 1990 to 2003 on trends and variability in yields of five crops and farmers' income at farm type and regional level in Europe considering farm characteristics and other factors. While Mediterranean regions are often characterized as most vulnerable to climate change, our data suggest effective adaptation to variable and changing conditions in these regions largely attributable to the characteristic farm types in these regions. We conclude that for projections of climate change impacts on agriculture, farm characteristics influencing management and adaptation should be considered, as they largely influence the potential impacts.
\end{abstract}

P. Reidsma $(\square) \cdot$ F. Ewert

Department of Plant Sciences, Plant Production Systems Group,

Wageningen University, P.O. Box 430, 6700 AK Wageningen,

The Netherlands

e-mail: pytrik.reidsma@wur.nl

F. Ewert

Crop Science Group, Institute of Crop Science and Resource

Conservation (INRES), Katzenburgweg 5, D-53115 Bonn,

Germany

\section{A. Oude Lansink}

Department of Social Sciences, Business Economics Group,

Wageningen University, P.O. Box 8130, 6700 EW Wageningen,

The Netherlands

\section{R. Leemans}

Department of Environmental Sciences,

Environmental Systems Analysis Group, Wageningen

University, P.O. Box 47, 6700 AA Wageningen,

The Netherlands
Keywords Climate change - Climate variability . Adaptive capacity · Farm management .

Agricultural vulnerability

\section{Introduction}

Global average surface temperature has increased with $0.74 \pm 0.18^{\circ} \mathrm{C}$ in the last century and is projected to increase by another $1.1-6.0^{\circ} \mathrm{C}$ in this century (IPCC 2007). Associated effects on agriculture have frequently been reported (Easterling et al. 2007). Assessments for European agriculture suggest that in northern Europe crop yields increase and possibilities for new crops and varieties emerge (Olesen and Bindi 2002; Ewert et al. 2005). In southern Europe, adverse effects are expected. Here, projected increases in water shortage reduce crop yields and the area for cropping which directly affects the livelihoods of Mediterranean farmers (Metzger et al. 2006).

Impacts of climate change on crop yields are generally assessed with mechanistic crop models (Easterling et al. 2007). Studies have been performed at different levels of organization: crops (see review of Tubiello and Ewert 2002), cropping systems (e.g., Tubiello et al. 2000), regional (Iglesias et al. 2000; Saarikko 2000; Trnka et al. 2004), continental (Harrison et al. 1995; Downing et al. 2000; Reilly 2002) and global (IMAGE team 2001; Parry et al. 2004).

It is widely recognized that site-specific crop models are developed for field scale application and that they cannot directly be used at higher aggregation levels (e.g., Passioura 1996; Marshall et al. 1997; Landau et al. 1998; Hansen and Jones 2000; Tubiello and Ewert 2002). While some efforts have been made to develop simplified regional scale models (e.g., Challinor et al., 2004; Potgieter et al. 2005), 
site-specific crop models are still widely used in large scale assessment studies of climate change impacts (Easterling et al. 2007). Site-specific crop models strongly emphasize biophysical factors such as climate and soil. The potential impacts of climate change and climate variability are relatively well understood for potential, water and nitrogen limited yields (e.g., van Ittersum et al. 2003). Actual yields, however, are also affected by other factors, such as pests and diseases, which depend on management (e.g., Landau et al. 1998). Such factors are often not considered in available crop models but can largely modify the considered climate change effects (Ewert et al. 2007).

Some examples are available in which statistical analyses have been used to explain climate change impacts on actual crop yields (Lobell and Asner 2003; Chen et al. 2004; Tao et al. 2006). However, results from these analyses are constrained by the risk of confounding (e.g., Bakker et al. 2005), especially when non-climatic factors are omitted as frequently happens. At the county level in the United States, Kaufmann and Snell (1997) showed that the relationship between maize yield and climate is influenced by input intensity, farm size and land use characteristics. Similar factors explain the relationship between crop yields and spatial climate variability in Europe (Reidsma et al. 2007).

The impact of climate change on farmers' income is influenced by changes in actual yields, but also by other factors such as commodity prices and land use changes. The economic vulnerability of agriculture to climate change is assessed either by coupling crop and economic models (Fischer et al. 2002; Antle et al. 2004; Parry et al. 2004; van Meijl et al. 2006; Kokic et al. 2007) or by Ricardian analyses (e.g., Mendelsohn et al. 1994; Mendelsohn 2007). The first type of assessment is mainly process-based. The main limitation of this approach is that crop model outputs that are used as input for the economic models do not refer to actual yields. The second type refers to empirical statistical analyses. The limitation here is that relationships for spatial variability are often directly applied to project temporal changes. Some recent attempts have been made to improve the Ricardian approach by including temporal variability (Deschenes and Greenstone 2006).

In Reidsma et al. (2007), we observed that farm characteristics and socio-economic conditions influence farm level responses to spatial climate variability. In this study we perform a statistical analysis to understand whether and to which extent responses to temporal changes and variability in climatic conditions are affected by these non-climatic factors. We combine agricultural statistics at regional and farm type level with climate data from 1990 to 2003 to assess the relative importance of climatic conditions, subsidies and farm characteristics on trends and variability in crop yields and farmers' income in the EU15 (i.e., the 15 member countries of the European Union before the extension in 2004). Results will improve understanding the role of management and adaptation with respect to climatic conditions, changes and variability herein.

\section{Methodology}

Scope of analysis and considered relationships

We consider the effects of climatic conditions in combination with subsidies and farm characteristics on two farm performance indicators, crop yield and farmers' income (Fig. 1). This provides more insight about the role of management and adaptation to changes and variability in climatic conditions. Management and adaptation can reduce potential impacts of climate change; the residual impacts determine the vulnerability (IPCC 2001).

As different crops respond differently to climatic conditions, yields of five crops (wheat, grain maize, barley, potato and sugar beet) are analyzed. Farmers' income is considered because it accounts for the direct impacts of climate on yields of different crops as well as the indirect substitution of inputs, introduction of different activities, and other potential adaptations to different climates (Mendelsohn et al. 1994). Farmers' income is represented by farm net value added per hectare $(f n v / h a)$ and farm net value added per annual work unit $(f n v / a w u)$. Fnv/ha measures economic performance per unit of land. Fnv/awu is a measure that enables comparison of farmers' income to gross domestic product per capita (gdp/cap) and can therefore relate farm performance to general socio-economic performance.

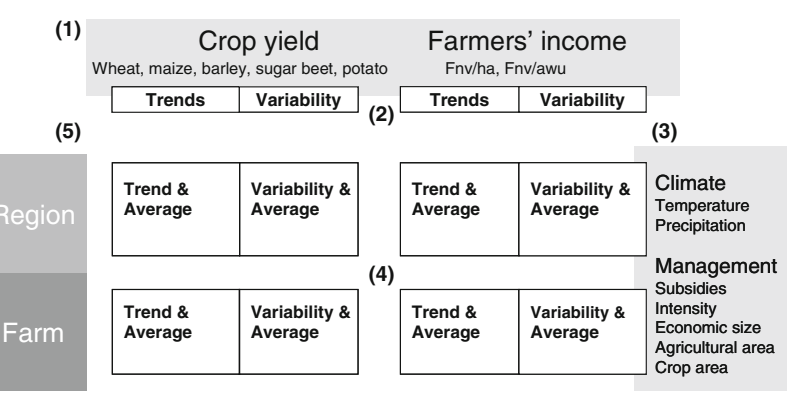

Fig. 1 Investigated relationships of climate and management impacts on crop yields and farmers' income at regional and farm type level. Relationships consider (1) two indicators of farm performance: crop yields and farmers' income in the form of (2) trends and variability; (3) two explaining factor groups: climate and management in the form of (4) trends, variability and averages and (5) two levels of organization: region and farm 
Vulnerability to climate change differs depending on the level of organization (O'Brien et al. 2004; Adger et al. 2005). At the regional level the agricultural sector as a whole may be able to adapt, but some farms will be more vulnerable than others. Therefore, we analyze agricultural vulnerability at both regional and at farm type level. Apart from the impacts of climatic conditions on crop yields and farmers' income, effects of farm characteristics and other factors influencing management are also considered in this analysis (Fig. 1).

We do not consider inter-annual variability in indicators and explaining factors explicitly, but concentrate on the trends and the average variability along the trends. For each region or farm type, the trend (and variability) in dependent (e.g., wheat yield) and independent (e.g., temperature) variables are calculated (Fig. 1). Subsequently, we compare trends (and variability) among regions (or farm types), instead of analysing changes within regions. Such an approach has previously been applied (e.g., Lobell and Asner 2003; Lobell et al. 2005) and allows to assess larger datasets coherently. Our aim is to obtain generic insights in the relative importance of climate and management factors to explain farm performance and therefore this approach is more appropriate compared to the one in which specific models are used for individual regions (e.g., Deschenes and Greenstone 2006).

Assessing impacts of climate change with historical time series is not straightforward, especially because time series data are relatively short and explaining factors can be confounding. Although the period 1990 to 2003 is too short to obtain signals of climate change, the trends and variability in climatic conditions allow us to analyze the influence of climatic conditions. Both at regional and farm type level, we firstly investigate the relationship between trends in climatic conditions and factors influencing management and trends in farm performance indicators. This provides insight into the influence of management and adaptation to the changes in climatic conditions on farm performance. We also analyze the impact of prevailing (average) conditions on trends in farm performance. Changes in farm performance may be more influenced by average conditions instead of changing conditions; considering both trends and averages in explaining factors reduces confounding.

Secondly, we analyze the relationship between temporal variability in climatic conditions and factors influencing management and variability in farm performance. These results will indicate what determines adaptation to variability in climatic conditions. Also, when analysing variability in farm performance, the influence of average conditions is considered. In "Statistical techniques" we will elaborate on this in more detail.
Data sources

Regional and farm type data are obtained from the Farm Accountancy Data Network (source: FADN-CCE-DG Agri and LEI) from 1990 to 2003. The FADN provides extensive data on farm characteristics of individual farms throughout the EU15. Data have been collected annually since 1989; for East Germany, Finland and Sweden since 1995. They have been used to evaluate the income of farmers and the consequences of the Common Agricultural Policy. In total, 100 HARM regions are distinguished with more than 50,000 sample farms. HARM is the abbreviation for a harmonized regional classification created by the Dutch Agricultural Economics Research Institute (LEI). It gives the opportunity to compare the different regional divisions of the EU15 used by Eurostat (NUTS2) and FADN.

At the regional level, farm characteristics are represented by variables representing land use, farm size and intensity (Table 1). Farm types are distinguished based on these variables (Table 2). Such a typology proved to be suitable for impact assessment studies (Andersen et al. 2006; Andersen et al. 2007). Policy is represented by total subsidies per hectare $(s u b s / h a)$. Other socio-economic conditions are not explicitly considered. Data on $g d p / c a p$ at regional level are only directly available from 1995 onward and Bakker et al. (2005) showed that impacts of gdp/cap on crop yields in this period were small.

Monthly temperature and precipitation data are obtained from the MARS project (http://www.marsop.info). Temperatures and precipitation of the first 6 months (JanuaryJune) are averaged to provide an indication of the temperature (tmean) and precipitation (pmean) conditions in the main growing period. MARS data are available per grid cell of $50 \times 50 \mathrm{~km}$ and are averaged per HARM region.

\section{Statistical techniques}

\section{Estimation of trends}

Trends in crop yields and income are estimated using the General Linear Model (GLM):

$y_{m i t}=\beta_{0 m i}+\delta_{m i} \cdot t+r_{m i t}$

where $y_{m i t}$ is the dependent variable, $m$ relates to crop yield or income, $\beta_{0 m i}$ is the intercept per region/farm type $i$, and $\delta_{m i}$ is the coefficient of the trend $(t=1,2, \ldots, N)$ per region/ farm type and the residual $r_{\text {mit }} \sim N\left(0, \sigma^{2}\right)$. Trends are assumed to be linear as was earlier observed for this period (Calderini and Slafer 1998; Ewert et al. 2005). The curve estimation procedure in SPSS 12 confirmed that this model performed best. For climate and management variables $x_{\text {nit }}$ the trend $\delta_{n i}$ is estimated similarly. 
Table 1 Data description and averages in the EU15 from 1990 to 2003

\begin{tabular}{|c|c|c|}
\hline Variable & Description & Average \\
\hline \multicolumn{3}{|c|}{ Dependent variables } \\
\hline Crop yield & Yield of specific crop (ton/ha) & Varies per crop $^{c}$ \\
\hline Fnv/ha & Farm net value added per hectare ${ }^{\mathrm{a}}(€)$ & $582^{\mathrm{c}}$ \\
\hline Fnv/awu & Farm net value added per annual working unit $(€)$ & $10883^{\mathrm{c}}$ \\
\hline \multicolumn{3}{|c|}{ Climatic conditions } \\
\hline Tmean & Mean temperature $\left({ }^{\circ} \mathrm{C}\right)$ of first half year & $9.8^{\mathrm{d}}$ \\
\hline Pmean & Mean precipitation $(\mathrm{mm})$ of first half year & $51.5^{\mathrm{d}}$ \\
\hline \multicolumn{3}{|c|}{ Policy factors } \\
\hline Subs/ha & Total subsidies/utilized agricultural area $(€)$ & $268^{\mathrm{c}}$ \\
\hline \multicolumn{3}{|l|}{ Land use } \\
\hline Ar/uaa & Arable area/utilized agricultural area $(-)$ & $0.53^{\mathrm{c}}$ \\
\hline Perm/uaa & Permanent cropping area/utilized agricultural area $(-)$ & $0.11^{\mathrm{c}}$ \\
\hline Grass/uaa & Grassland area/utilized agricultural area $(-)$ & $0.32^{\mathrm{c}}$ \\
\hline Crop_pr & Crop area/total arable area $(\%)$ & Varies per crop $^{c}$ \\
\hline \multicolumn{3}{|l|}{ Size } \\
\hline Ec_size & Economic size $^{\mathrm{b}}$ (ESU) & $51.4^{\mathrm{c}}$ \\
\hline Uaa & Utilized agricultural area (ha) & $70.0^{\mathrm{c}}$ \\
\hline \multicolumn{3}{|l|}{ Intensity } \\
\hline Fert/ha & Costs of fertilizers and soil improvers per hectare $(€)$ & $92.6^{\mathrm{c}}$ \\
\hline Prot/ha & Costs of crop protection products per hectare $(€)$ & $67.3^{\mathrm{c}}$ \\
\hline Irr_perc & Irrigated percentage of utilized agricultural area (\%) & $7.2^{\mathrm{c}}$ \\
\hline
\end{tabular}

${ }^{a}$ Farm net value added corresponds to the payment for fixed factors of production (land, labor and capital), whether they are external or family factors. As a result, holdings can be compared irrespective of the family/non-family nature of the factors of production employed. Fnv $=$ total output - total intermediate consumption + balance current subsidies and taxes - depreciation

b The economic size is determined on the basis of the overall standard gross margin of the holding. It is given in European Size Units (ESU); one ESU corresponds to a standard gross margin of $€ 1,200$

c Source: FADN

d Source: MARS

We test for stationarity along the linear trend $\delta_{m i}$ by estimating serial correlations between residuals using $r_{m i t}-r_{m i, t-1}=\alpha_{m i}+\gamma_{m i} \cdot r_{m i, t-1}+\varepsilon_{m i t}$. Stationarity exists if the mean and variance of the error term is constant. The test shows that for a few $m$ in several $i, \gamma_{m i}$ is significant, which implies that there is serial correlation between residuals $r_{m i t}$. Hence, not all models have a constant variance. This implies that our parameter estimates are consistent, but not necessarily all are efficient. However, this does not invalidate our approach since we explain differences in trends requiring consistent estimates rather than efficient parameter estimates.

\section{Analysis of trends}

A second group of GLMs are used to identify the extent to which the independent variables combined in one model can explain trends in yields and income determined by Eq. 1. The general set-up of this GLM is:

$\delta_{m i}=b_{0 m}+b_{m n} \cdot x_{n i}+e_{m i}$ where $\delta_{m i}$ is the estimated trend parameter obtained from estimation of Eq. 1, $x_{n i}$ is a vector of $n$ explanatory variables (trend $\delta_{n i}$ or average of $x_{n i t}$; Fig. 2) and $e_{m i}$ is an error term. At the farm type level, multilevel models (Snijders and Bosker 1999; Reidsma et al. 2007) are used with the farm type dimensions as explaining factors $x_{n i}$ which have a value of 0 or 1 and tmean, pmean and subs/ha as covariates (continuous variables). A multilevel model controls for regional effects, when analysing data from farm types in different (HARM) regions. This allows analysing the difference between farm types within regions. At the regional level, all regions with less than 5 years of data and arable land $<10,000$ ha are excluded from the analysis. Little data occur mainly in less favored regions where crops are cultivated on a very small area. At the farm type level all farm types with less than 3 years of data are excluded; to analyze the sensitivity also models requiring more years of data per farm type are applied.

A consideration when applying Eq. 2 is the possible heteroskedasticity in the model. Estimates of $\delta_{m i}$ from 
Table 2 Farm typology; each farm type is characterized by a land use, size and intensity dimension

\begin{tabular}{|c|c|c|}
\hline \multicolumn{2}{|c|}{ Dimension and type } & Definition \\
\hline \multicolumn{2}{|c|}{ Land use } & (EU type), land use type rule ${ }^{\mathrm{a}}$ \\
\hline 1 & Arable/cereal & $(1+6),<12.5 \%$ fallow and $\geq 50 \%$ cereals \\
\hline 2 & Arable/fallow & $(1+6), \geq 12.5 \%$ fallow \\
\hline 3 & Arable/specialized crops & $(1+6), \geq 25 \%$ of arable land in specialized crops \\
\hline 4 & Arable/others & $(1+6)$, other arable \\
\hline 5 & Dairy cattle/permanent grass & $(4.1), \geq 50 \%$ grass and $<50 \%$ temporary grass \\
\hline 6 & Dairy cattle/temporary grass & $(4.1), \geq 50 \%$ grass and $\geq 50 \%$ temporary grass \\
\hline 7 & Dairy cattle/land independent & $(4.1), \mathrm{UAA}=0$ or $\mathrm{LU} / \mathrm{ha} \geq 5$ \\
\hline 8 & Dairy cattle/others & (4.1), other dairy cattle \\
\hline 9 & Beef and mixed cattle/permanent grass & (4.2 and 4.3$)$, as 5 \\
\hline 10 & Beef and mixed cattle/temporary grass & (4.2 and 4.3), as 6 \\
\hline 11 & Beef and mixed cattle/land independent & (4.2 and 4.3), as 7 \\
\hline 12 & Beef and mixed cattle/others & (4.2 and 4.3), other beef and mixed cattle \\
\hline 13 & Sheep and goats/land independent & $(4.4)$, as 7 \\
\hline 14 & Sheep and goats/others & (4.4), other sheep and goats \\
\hline 15 & Pigs/land independent & $(5.1)$, as 7 \\
\hline 16 & Pigs/others & (5.1), other pigs \\
\hline 17 & Poultry and mixed pigs/poultry & $(5.2)$ \\
\hline 18 & Mixed farms & (7) \\
\hline 19 & Mixed livestock & $(8)$ \\
\hline 20 & Horticulture & (3) \\
\hline 21 & Permanent crops & (2) \\
\hline \multicolumn{3}{|c|}{ Size } \\
\hline 1 & Small scale & $<16 \mathrm{ESU}$ \\
\hline 2 & Medium scale & $\geq 16 \mathrm{ESU}$ and $<40 \mathrm{ESU}$ \\
\hline 3 & Large scale & $\geq 40 \mathrm{ESU}$ \\
\hline \multicolumn{3}{|c|}{ Intensity } \\
\hline 1 & Low intensity & Total output per ha $<€ 500$ \\
\hline 2 & Medium intensity & Total output per ha $\geq € 500$ and $<€ 3,000$ \\
\hline 3 & High intensity & Total output per ha $\geq € 3,000$ \\
\hline
\end{tabular}

Eq. 1 may be more precise in regions with large agricultural areas than in regions with smaller agricultural areas (e.g., Deschenes and Greenstone 2006). As we have data at farm type level we can asses the relationship between heteroskedasticity and precision at regional level. An analysis of variances shows that the variance in farm type level trends $r_{\text {mit }}$ per HARM region is not dependent on agricultural area or other variables used in our regression, so heteroskedasticity of this form is not present. A second form of heteroskedasticity can occur when $e_{m i}$ from Eq. 2 is dependent on the values of the independent variables. This is tested with the Breusch-Pagan test, which shows that there is no relationship between $e_{m i}$ and the independent variables.

Although the tests indicate that heteroskedasticity is not a problem, we use weighted least squares (WLS) instead of ordinary least squares (OLS) to provide optimal estimates. Agricultural areas vary largely per region and regions with small agricultural areas have a relatively large influence with OLS. Therefore, the crop area is used as the weight for crop yields (specific per crop) and the utilized agricultural area for farmers' income.

The impact of $x_{n i}$ on $\delta_{m i}$ is determined by the parameter estimates $b_{m n}$. In order to assess the relative impact of different variables on the trends, we calculate the elasticity at the mean for each parameter estimate $b_{m n}$ as:

$\varepsilon\left(b_{m n}\right)=b_{m n} \cdot\left(\frac{\bar{x}_{n i}}{\bar{\delta}_{m i}}\right)$

\section{Analysis of variability}

Variability in crop yields and income is based on the relative anomaly from the expected yields or income variables. At the regional level, expected yields and income are derived from the trend in Eq. 1. The absolute anomaly is given by its error term, i.e., $=r_{m i t}$. The relative anomaly is 


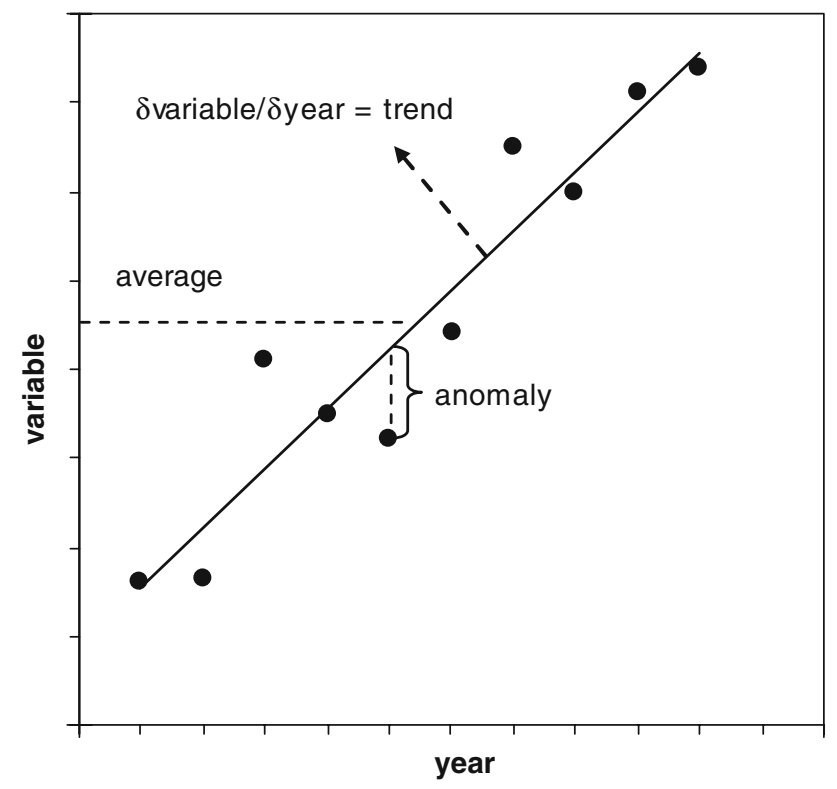

Fig. 2 Measures used in the statistical analysis. Trends of dependent variables are related to trends and averages of independent variables. Variability is measured by the average of relative anomalies. Variability in dependent variables are related to variability and averages of independent variables

computed as the ratio of the absolute anomaly and expected income or yield, i.e., $r_{m i t} /\left(\beta_{0 m i}+\delta_{m i} \cdot t\right)$. Complete time series are not always available at the farm type level, which results in less reliable trend estimates. As only few trends are significant, we use the average crop yield or income between 1990 and 2003 per farm type as indicator of the expected yield or income when computing the absolute and relative anomaly.

The same approach as for the analysis of trends is used. Per $i$, variability $v_{m i}$ is measured as the average relative anomaly without considering positive or negative signs [as $r_{m i t} \sim N\left(0, \sigma^{2}\right)$ ]. Variability $v_{n i}$ in explanatory factors $x_{n i t}$ is similarly measured. Subsequently, at the regional level GLMs are used to identify the combined effect of the explanatory variables $x_{n i}$ (variability $v_{n i}$ or average of $x_{n i t}$ ). At the farm level, multilevel models (Snijders and Bosker 1999; Reidsma et al. 2007) are used to analyze the effects of farm type characteristics on yield and income variability.

\section{Results}

Regional level

\section{Trends in crop yields and income variables}

Both positive and negative trends are observed in crop yields, but as time series are short, only around $25 \%$ of the trends are significant (Fig. 3). Generally, crop yield trends are positive and higher in temperate regions (e.g., France and Germany), but high trends are also observed in Spain, while trends in Italy are mainly negative. The spatial pattern is different for farmers' income. Significantly positive trends in fnv/ha are found in Greece, Portugal, Italy and Ireland and some regions in Spain, while trends are mainly negative in temperate and Nordic regions. The trend in fnv/awu is positive in almost all regions and is significant in around half of the regions, mainly in the Mediterranean.

These differences in trends can be partly explained by trends in climatic conditions and management (Table 3, first column per dependent variable; Fig. 4). Results of the GLMs indicate a large negative effect of the trend in temperature (tmean) on crop yield trends; the elasticity is large and negative for all crop yield trends. Where temperature increases faster with time, crop yield trends are lower. Also the effect of the trend in precipitation (pmean) is mainly negative, implying that a decreasing pmean has not reduced yield trends.

The impact of trends in management variables is similar for all crops. Effects on yield trends are generally positive for trends in economic size (ec_size) and fertilizer use (fert/ ha) suggesting that changes in size and intensity can influence climate impacts on crop yields.

Differences in trends may also be explained by differences in prevailing conditions (Table 3, second column per dependent variable). Consideration of averages in the analysis indicates whether prevailing conditions are of importance. Results of the GLMs show that the elasticity of average tmean is large, but the effect differs per crop. The effect of average pmean is also not coherent, but significantly concave for barley and negative for maize. Hence, spatial variability in the calculated averages of climatic
Fig. 3 Selected examples of trends from 1990 to 2003 in a wheat yield (t/ha/year) and $\mathbf{b}$ fnv/ha (€/year)
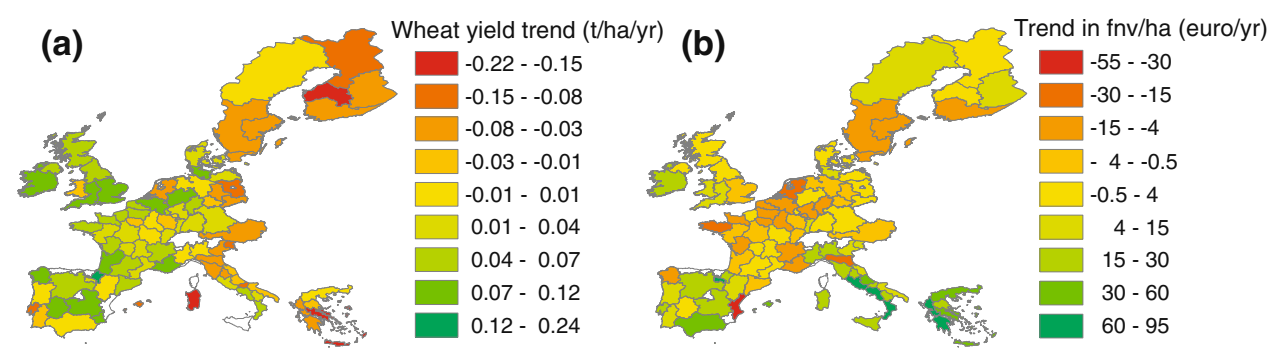


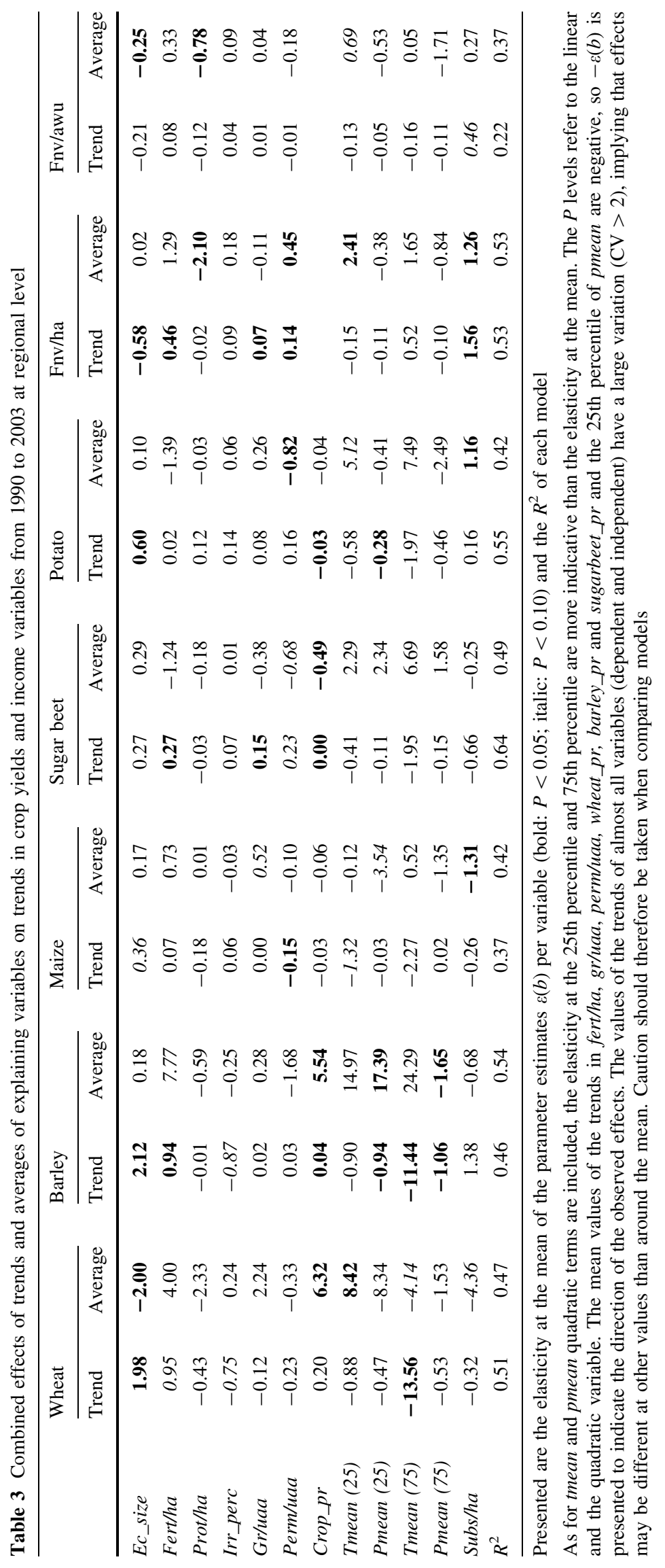


Fig. 4 Trends from in 19902003 in a tmean $\left({ }^{\circ} \mathrm{C} /\right.$ year $)$ and $\mathbf{b}$ pmean (mm/year) (a)

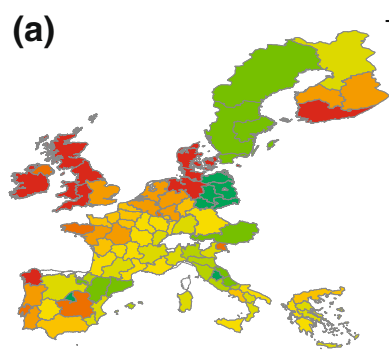

Trend in tmean $\left({ }^{\circ} \mathrm{C} / \mathrm{yr}\right)$

$-0.02-0.03$

$0.04-0.05$

$0.06-0.07$

$0.07-0.08$

$0.09-0.10$

$0.11-0.13$

$0.14-0.16$

$0.17-0.20$

$0.21-0.26$ (b)

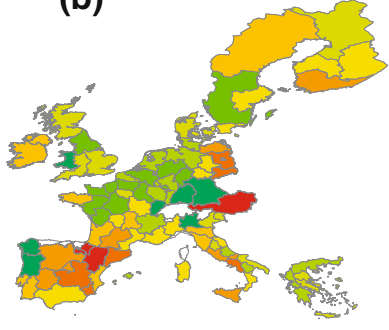

Trend in pmean $(\mathrm{mm} / \mathrm{yr})$

$-2.95--2.44$

$-2.43--1.04$

$-1.03--0.47$

$-0.46--0.13$

$-0.12-0.20$

$0.21-0.52$

$0.53-0.80$

$0.81-1.13$

$1.14-2.56$ conditions does not have the same effect as temporal change (i.e., trends) in climatic conditions.

Considering management factors, the trends in wheat and barley yields are larger where the average crop area (crop_pr) is higher; for sugar beet and potato the opposite is the case. Similar results were obtained for the effects of trends in $c r o p \_p r$, suggesting that the effects of crop_pr on yield trends are of more general nature. In contrast, the effect of average ec_size is negative for the wheat yield trend, while the effect of the trend in ec_size was positive. This suggests that smaller farms that grow fast have highest wheat yield trends. Policies also influence yield trends with high subsidies (subs/ha) having a negative impact on most yield trends.

Trends in fnv/ha and fnv/awu are not significantly influenced by trends in climatic conditions. Trends in other factors have more impact; trends in subs/ha, fert/ha, gr/uaa and perm/uaa have a significant positive impact on the trend in fnv/ha. Subsidies (subs/ha) have a direct effect on income, an increasing input intensity (fert/ha) can indirectly increase output intensity and increasing other land uses (gr/uaa and perm/uaa) can lead to a more profitable use of the land.

When prevailing conditions are considered, it is clear that trends in fnv/ha and fnv/awu increase with average tmean which was not the case for yields of most crops. This suggests that in Mediterranean regions, with generally a less favorable climate, more adaptations took place (related to trends as mentioned above) compared to temperate regions. Apparent is that regions with a large average $e c \_s i z e$ and large trends herein (e.g., France and Germany), have lower trends in both $f n v / h a$ and fnv/awu. An increase in the average farm size is thus positively related to trends in crop yield, but negatively to the trend in farmers' income. Hence, although farms in these regions do not seem to be particularly vulnerable to changes in climatic conditions, there is some indication for increasing vulnerability related to farmers' income.

\section{Variability in crop yields and income variables}

Average relative anomalies in regional crop yields from 1990 to 2003 range between 5 and 15\% for most crops and are somewhat larger in Mediterranean and Scandinavian regions, where yields are generally lower (Fig. 5). Maize yield anomalies are smaller in Greece and Spain, where maize yields are higher. The spatial pattern in variability of fnv/ha and fnv/awu is similar to most crop yields, but the average anomalies are larger.

The models show that a high variability in pmean (which is especially high in Mediterranean regions; average is $19 \%$ ) is positively related to variability in wheat and barley yield, but negatively to variability in maize, sugar beet and potato yields (Table 4, first column per dependent variable). The impact of a high variability in tmean (generally higher in northern regions; average is $0.59^{\circ} \mathrm{C}$ ) is negative for all crops, but only significant for wheat. A negative relationship suggests that the extent of temperature variability is not an import contributor to crop yield variability. However, the effect of temperature variability may increase when temperature shifts away from the cropspecific optimum. As the base temperature is not taken into account here, relationships can be confounded; therefore we also consider relationships with average conditions in the following paragraph. A management factor that significantly contributes to lower yield variability is a low variability in crop_pr.

Variability in yields and income is also related to average climatic and management conditions (Table 4, second column per dependent variable), to complement the analysis with the impact of prevailing conditions. Yield variability of all crops increases with average tmean [ $\varepsilon$ (tmean) is higher at the 75 th percentile compared to the 25th percentile]. Effects of pmean are mainly convex, implying lowest variability at average levels of precipitation. The impact of management variables on yield variability differs by crop. Several significant effects are observed. For example, more irrigation (irr_perc) decreases variability in maize and potato yields.

Variability in fnv/ha and fnv/awu is mainly influenced by variability in fertilizer use (fert/ha) and crop protection use (prot/ha), related to the intensity of farming. Variability in tmean increases variability in $f n v / h a$, in contrast to variability in crop yields. The GLM including average conditions shows that variability in fnv/ha and fnv/awu has a negative elasticity at the 25 th percentile for tmean, but 
Fig. 5 Average relative anomaly (\%) from 1990 to 2003 in 100 HARM regions for a wheat yield, b barley yield, c maize yield, $\mathbf{d}$ sugar beet yield, e potato yield, f $f n v / h a$ and $\mathbf{g}$ fnv/awu
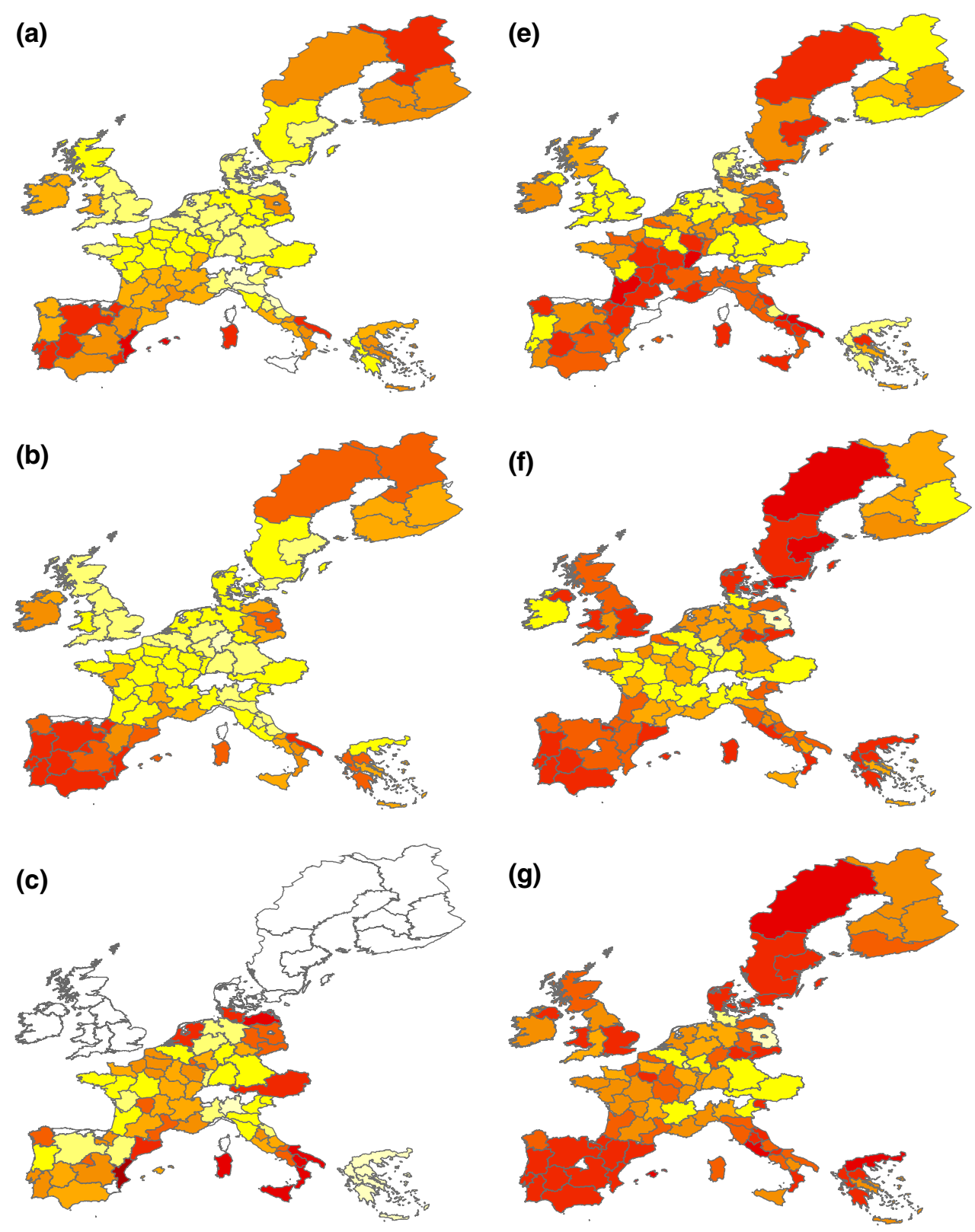

(d)

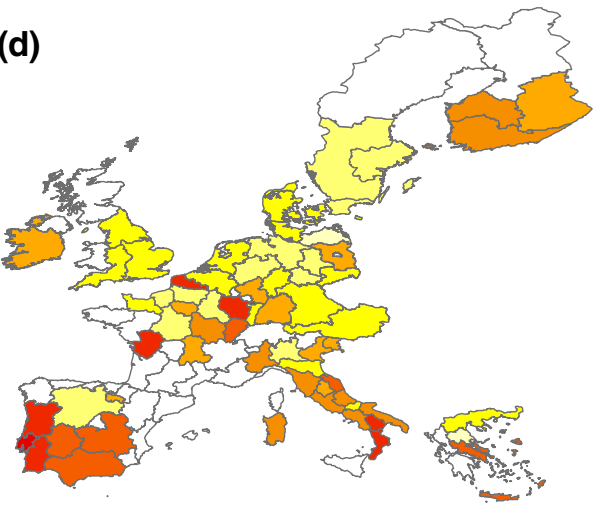
Average anomaly (\%)

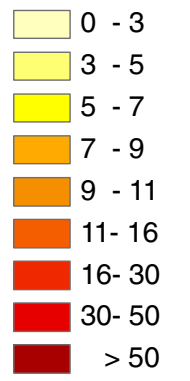




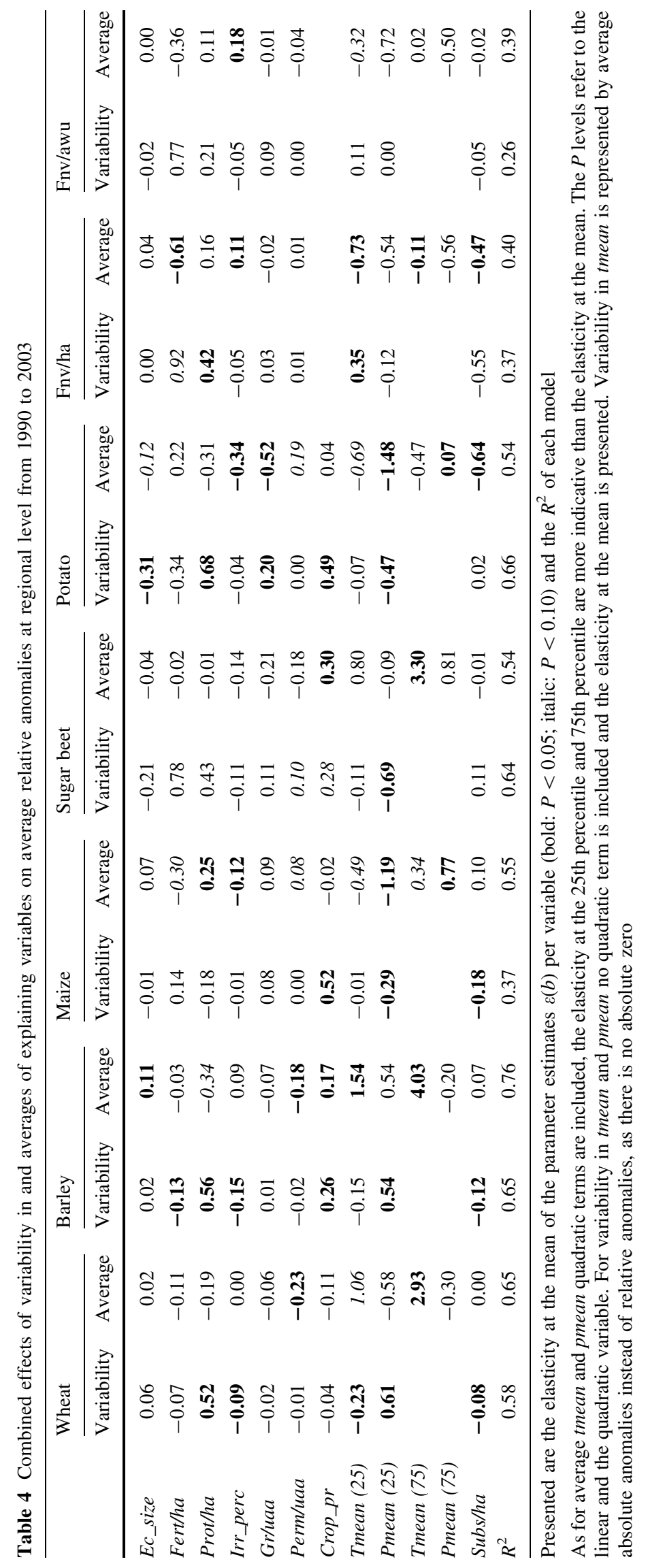


almost zero at the 75 th percentile, implying lowest variability around the 75 th percentile $\left(11.9^{\circ} \mathrm{C}\right)$. Hence, although Fig. 5f suggests a concave temperature effect; the model indicates that the high variability in some Mediterranean regions is mainly due to other factors. More irrigation (irr_perc) increases income variability significantly; applying more fertilizers (fert/ha) and receiving many subsidies (subs/ha) decrease income variability. The effect of irrigation may be related to regions with a higher irr_perc being dryer or growing more demanding crops, making agriculture riskier. The negative effect of average pmean indeed suggests that a low precipitation increases income variability, although the effect is not significant.

Farm type level

\section{Trends in crop yields and income variables}

At farm type level, inter-annual variability in crop yields and farmers' income is generally large and for most farm types time series are shorter than 14 years. There are also some temporal changes in the farm types. While the number of small scale, low intensive farm types declines, the number of large scale, intensive farm types tends to increase. The trend models estimating $\delta_{m i}$ per farm type within each region result in few significant trends in crop yields and income variables (not shown).

Despite these results, we analyze whether the differences in trends can be attributed to differences in farm types. We consider only farms with more than 10 years of data are; considering fewer farms gave unreliable results. We see that small scale farms have significantly higher trends for most crop yields and fnv/ha compared to large scale farms, while the opposite is observed for fnv/awu (not shown). With respect to farm intensity and land use, few significant estimates are found. More significant differences between farm types are observed in region-specific models, but the effects of farm type dimensions do not point into the same direction. Hence, trends differ among regions in relation to climate and management conditions, but the effect of management cannot be generalized across regions.

\section{Variability in crop yields and income variables}

In contrast to the results about the trends, there are significant differences between farm types with regard to variability in crop yields and farmers' income. Multilevel models correcting for regional effects show that yield variability significantly decreases with increasing farm size for most crops (Table 5). A low intensity has a significant positive impact on yield variability of all crops, except for wheat. Also, yield variability is significantly different among land use types. All land use types are included in the analysis as also on non-arable land use types field crops are cultivated. Yield variability of cereals is significantly lower on arable/cereal farms compared to other land use types, while yield variability of sugar beet and potato is lower on arable/specialized crops farms.

Variability in both fnv/ha and fnv/awu is larger on small and medium farms than on large farms. Variability is also significantly higher on low intensive farm types (10\%) and medium intensive farm types (around 2\%) compared to high intensive farms. The effect of intensity was also observed at the regional level (represented by fert/ha).

For income variability we compare arable farm types with other land use types. Variability in $f n v / h a$ and $f n v / a w u$ is higher on arable farms than on dairy cattle farms, but lower than on farms with pigs, horticulture and permanent crops. For arable farm types the variability in fnv/ha is lowest on arable/cereal farms. As observed in the regional analysis more grassland area thus decreases income variability, and more permanent cropping area increases income variability.

The influence of average tmean is similar to the regional results for crop yield variability, but not for income variability. Thus, impacts on income at aggregated levels can be confounded by farm characteristics. Variability in pmean also affects yield variability, and in contrast to the regional level no negative effects are observed. When analyzing variability among farm types within regions, farm characteristics account for these negative effects. More subsidies and variability herein lead to a higher variability in crop yields and income, which is also in contrast to the results from the regional analysis. Subsidies are coupled to regional yield levels, so the regional level impact may be confounded as higher yields lead to lower variability. A multilevel model corrects for this effect.

\section{Discussion}

Scope and methods of analysis

This is one of the first empirical studies linking farm characteristics to impacts of trends and variability in climatic conditions on European agriculture. Our analysis regresses observed data on climatic conditions, subsidies and farm characteristics against crop yields and income at regional and farm type level. Considering trends, variability and averages in the analysis allows for addressing the role of changes in climatic conditions, variability herein and prevailing climatic conditions for farm performance. This provides insights in the relative importance of climate change and associated climate variability for European agriculture. With regard to climate variability, we focus on 
Table 5 Fixed effects in mixed models correcting for regional differences, of farm type dimensions (size, intensity and land use) and subsidies and climate on crop yield and income variability (relative anomalies) between 1990 and 2003 in the EU15

\begin{tabular}{|c|c|c|c|c|c|c|c|}
\hline & Wheat & Barley & Maize & Sugar beet & Potato & Fnv/ha & Fnv/awu \\
\hline Intercept & 25.71 & 19.52 & 37.55 & 15.05 & 10.65 & 9.31 & 13.94 \\
\hline Small scale & 2.84 & 1.81 & 2.01 & 1.21 & 0.17 & 7.91 & 10.18 \\
\hline Medium scale & 1.62 & 0.84 & 1.49 & 0.42 & -0.65 & 0.72 & 1.10 \\
\hline \multicolumn{8}{|l|}{ Large scale } \\
\hline Low intensity & 0.32 & 1.92 & 5.22 & 8.59 & 4.87 & 10.28 & 10.15 \\
\hline Medium intensity & -1.00 & -1.29 & 0.11 & 0.86 & 1.56 & 2.26 & 3.25 \\
\hline \multicolumn{8}{|l|}{ High intensity } \\
\hline \multicolumn{8}{|l|}{ Arable/cereal } \\
\hline Arable/fallow & -0.09 & 0.08 & -2.03 & -0.15 & -1.60 & 1.60 & -0.86 \\
\hline Arable/specialized crops & 0.16 & 0.94 & 1.52 & -2.33 & -6.86 & 0.94 & 1.74 \\
\hline Arable/others & 4.18 & 2.87 & 5.18 & 1.96 & 1.26 & 2.41 & 1.16 \\
\hline Dairy cattle/permanent grass & 4.65 & 1.92 & 5.43 & 3.79 & 1.55 & -3.79 & -5.21 \\
\hline Dairy cattle/temporary grass & 3.07 & -1.80 & 5.73 & 2.47 & 5.56 & -6.03 & -8.86 \\
\hline Dairy cattle/land independent & 11.05 & 10.20 & -2.19 & 8.31 & -4.34 & 5.01 & -3.97 \\
\hline Dairy cattle/others & 1.44 & -0.85 & 1.93 & 2.48 & 2.02 & -3.33 & -5.90 \\
\hline Beef and mixed cattle/permanent grass & 1.34 & 0.59 & 3.36 & 11.35 & 6.34 & -2.10 & -2.93 \\
\hline Beef and mixed cattle/temporary grass & 1.35 & -2.26 & 5.93 & -3.22 & -9.66 & -0.99 & -1.43 \\
\hline Beef and mixed cattle/land independent & -3.66 & -2.27 & 2.48 & & & 4.13 & -1.32 \\
\hline Beef and mixed cattle/others & 3.70 & -3.13 & -1.63 & 1.83 & -0.07 & -2.23 & -5.28 \\
\hline Sheep and goats/land independent & 5.34 & 4.17 & 6.52 & -6.69 & 15.84 & -1.71 & -8.78 \\
\hline Sheep and goats/others & 4.87 & 0.65 & 6.21 & 2.63 & 0.13 & -3.58 & -5.47 \\
\hline Pigs/land independent & 2.22 & 3.07 & 3.55 & 2.79 & 0.18 & 27.05 & 16.11 \\
\hline Pigs/others & -1.07 & -1.88 & -0.81 & 0.37 & 5.06 & 40.09 & 36.51 \\
\hline Poultry and mixed pigs/poultry & -1.61 & 1.12 & 3.79 & -7.47 & -3.05 & 10.42 & 1.45 \\
\hline Mixed farms & -0.04 & -0.78 & 2.44 & 1.67 & 1.19 & 0.06 & -1.76 \\
\hline Mixed livestock & -0.57 & -0.66 & 0.47 & 1.17 & -0.46 & 1.02 & -2.46 \\
\hline Horticulture & 4.46 & 14.93 & 4.60 & 6.90 & 5.60 & 7.64 & -0.86 \\
\hline Permanent crops & 6.39 & 6.58 & 6.93 & 5.67 & 5.42 & 4.53 & 3.12 \\
\hline Tmean (average; 25) & 0.39 & 0.60 & -0.39 & 0.27 & 0.34 & 0.03 & 0.15 \\
\hline Pmean (average; 25) & -0.18 & -0.12 & 0.17 & 0.12 & 0.09 & 0.07 & 0.02 \\
\hline Tmean (average; 75) & 2.38 & 2.25 & 1.41 & 2.24 & 0.77 & 0.27 & 0.61 \\
\hline Pmean (average; 75) & 0.29 & 0.22 & 0.38 & -0.19 & -0.06 & -0.21 & -0.29 \\
\hline Subs/ha (average) & 0.02 & 0.00 & -0.01 & 0.12 & 0.04 & 0.02 & 0.00 \\
\hline Tmean (variability) & -0.11 & -0.13 & 0.02 & -0.11 & -0.19 & -0.08 & -0.08 \\
\hline Pmean (variability) & 0.25 & 0.08 & 0.21 & 0.08 & 0.00 & -0.01 & 0.00 \\
\hline Subs/ha (variability) & 0.07 & 0.03 & 0.00 & 0.08 & 0.12 & 0.16 & 0.18 \\
\hline
\end{tabular}

For farm type dimensions, parameter estimates of fixed effects are presented and significance levels $(P<0.05$ : bold; $P<0.10$ : italic $)$ refer to the difference with the reference per dimension (large scale, high intensity, arable/cereal). The estimates remain (almost) constant when including either averages or variability in climate variables and subs/ha. For tmean, pmean and subs/ha elasticities are presented (as in Table 3 and 4 )

the extent and not on the direction of inter-annual variability, as the regional differences in the direction of interannual climate variability do not allow a generic approach to obtain generic insights in the influence of management. Interactions between climate and management are explored for specific regions in Reidsma et al. (2008).

Our aim in this study is not to estimate climate impacts for each region or farm type, but to obtain insight in the relative importance of climatic conditions, subsidies and farm characteristics for explaining crop yield and income at different levels of organization. Although the FADN data base comprises only 14 years of data, the spatial extent and the large numbers of farms included in the data, provides a unique opportunity to analyze farm performance in relation to these factors. Analysing trends among regions instead of within regions reduces confounding of effects. We 
Fig. 6 Summary presentation of impacts of climate and management on farm performance at two levels of organization. Impacts are: + positive, +- concave, -+ convex, - negative, $+/$ - differs per variable. The variables are explained in Tables 1 and 2 with $(a)$ average, $(t)$ trend and (v) variability

\begin{tabular}{l|l}
\multicolumn{1}{c}{ Crop yield } & \multicolumn{2}{c}{ Farmers' income } \\
Wheat, maize, barley, sugarbeet, potato & \multicolumn{2}{c}{ Fnv/ha, Fnv/awu } \\
\begin{tabular}{|c|c|c|c|}
\hline Trends & Variability \\
\cline { 3 - 4 } & Trends & Variability \\
\hline
\end{tabular}
\end{tabular}

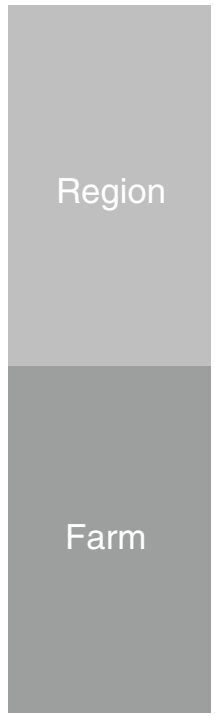

\begin{tabular}{|c|c|c|c|c|}
\hline $\begin{array}{l}\text { Climate } \\
\text { tmean }(\mathrm{t}) \text { - } \\
\text { pmean }(\mathrm{t}) \text { - } \\
\text { Management } \\
\text { ec_size }(\mathrm{t})+ \\
\text { fert/ha }(\mathrm{t})+ \\
\text { crop_pr(a) +/- } \\
\text { subs/ha }(\mathrm{a})-\end{array}$ & $\begin{array}{l}\text { Climate } \\
\text { pmean }(v)+/- \\
\text { tmean(a) + } \\
\text { tmean(v) - } \\
\text { pmean(a) - + } \\
\text { Management } \\
\text { crop_pr(v) + } \\
\text { subs/ha (v) - }\end{array}$ & $=-1$. & $\begin{array}{l}\text { Climate } \\
\text { tmean }(a)+ \\
\text { Management } \\
\text { subs/ha }(a / t)+ \\
\text { fert/ha }(a / t)+ \\
\text { ec_size }(a / t)- \\
\text { prot/ha }(a)- \\
\text { perm/uaa }(a / t)+\end{array}$ & $\begin{array}{l}\text { Climate } \\
\text { tmean(a) - } \\
\text { tmean( v) + } \\
\text { Management } \\
\text { fert/ha (v) + } \\
\text { prot/ha (v) + } \\
\text { subs/ha (a) - } \\
\text { fert/ha (a) - } \\
\text { irr_perc(a) + }\end{array}$ \\
\hline$x$ & $\begin{array}{l}\text { Climate } \\
\text { tmean }(\mathrm{a})+ \\
\text { pmean }(\mathrm{v})+ \\
\text { Management } \\
\text { land use (arable) - } \\
\text { size - } \\
\text { intensity - } \\
\text { subs/ha }(\mathrm{v})+\end{array}$ & & $x$ & $\begin{array}{l}\text { Climate } \\
\text { tmean }(\mathrm{a})+ \\
\text { Management } \\
\text { land use (other) - } \\
\text { size - } \\
\text { intensity - } \\
\text { subs/ha (v) + }\end{array}$ \\
\hline
\end{tabular}

acknowledge that when trends are non-linear, relationships can still be confounded. Therefore, the trends are regressed against both trends and averages of explaining variables and at two levels of organization (farm type and region). By comparing results from the multiple analyses, confounding relationships can be partly uncovered.

Technological development has a large impact on yield trends in Europe (Ewert et al. 2005), but is not explicitly addressed in our analysis. Technology development is a combination of several factors, of which some are considered here. Our analysis provides information about the relative importance of factors for the variability in trends. It does not attempt to explain trends due to technology development. The obtained results point to the importance of climate, farm characteristics and regional conditions for changes in yield trends.

Assumptions underlying the analysis and the aggregation of data have been tested for validity. At the regional level intensity is represented by fertilizer use $($ fert/ha) and crop protection use ( $\mathrm{prot} / \mathrm{ha}$ ) in $€ / \mathrm{ha}$. The two-way relationship between these regional-level variables and dependent variables can violate the basic assumption of independence. Testing on endogeneity using instrumental variables showed that these variables are exogenous. They are not corrected for price effects, since (1) price changes are relatively small in relation to differences between regions, (2) temporal changes in prices are similar among regions and (3) data on price indices are only available after 1995.

Temperature and precipitation data are averaged for the first 6 months of the year, which represent the main growing period. The start and length of the growing season differ depending on the region and crop, but using the same period allows better comparisons. Including or excluding other months does not have a large impact on the results.

The used farm typology is a common typology for the whole EU15 (Andersen et al. 2006). Thresholds defining the farm type dimensions are the same for all regions. As only few classes are distinguished per farm type dimension (Table 2), the number of different farm types is small in some regions. Increasing the number of classes or changing the thresholds, especially for intensity, could provide additional detail on the impacts and adaptation. Nevertheless, this study shows that with the limited number of farm types, differences in their responses to climate variability and trends are obvious.

Factors explaining trends and variability in farm performance at multiple levels

Trends in climatic conditions, as well as prevailing climatic conditions, have an impact on trends and variability in crop yields in the EU15. However, the impacts are influenced by policy and management conditions, and differ depending on the level of organization (see summary in Fig. 6). Our results suggest that in the analyzed period the change in temperature (i.e., trend) had a larger impact on crop yield trends than the average temperature. Crop yield trends have been generally larger in temperate regions compared to Mediterranean regions (Calderini and Slafer 1998; Ewert et al. 2005), but this is less apparent for the period from 
1990 to 2003. This is consistent with Ewert et al. (2005), who suggested that relative yield changes are converging for EU15 countries.

The high relative impacts of prevailing climatic conditions on farm performance indicate that regions with similar climatic conditions change and adapt in a similar way. The relative impact of average temperature in explaining differences in crop yield trends among regions is large compared to those of policy or management variables. Nevertheless, consideration of these non-climatic effects is required to sufficiently explain differences in climate impacts across regions. Trends in economic size and fertilizer use clearly influence the differences in yield trends.

A high variability in precipitation (pmean) has a large impact on crop yield variability and is of more concern than variability in temperature (tmean). At regional level a high variability in pmean can also lead to reduced yield variability of some crops, but the farm type level analysis shows that when we account for within regional differences, this is not the case. At farm type level, a higher intensity, larger scale and specialized land use reduce crop yield and income variability.

Our results confirm earlier observations (e.g., Thorhallsdottir 1990) suggesting that the impact of climate on yield and income variability is especially important at higher aggregation levels. At the farm type level, farm characteristics are more important. A change in the intensity of farming or farm size will have more impact on farm performance than changes in climatic conditions. Understanding of the mechanisms underlying climatic effects on crop yields at different levels of organization remains difficult. The present analysis is explorative, but our results suggest that the approach to model responses to climate change will differ depending on the aggregation level as (1) the importance of factors changes depending on the level and (2) resulting impacts at one aggregation level do not necessarily apply for other levels.

Vulnerability in crop productivity and income

Spatial variability in crop yields throughout the EU15 is not related to spatial variability in income $(f n v / h a)$ (Reidsma et al. 2007). The present analysis shows that climate effects on crop yields and fnv/ha is also different when analyzed over time. Variability in crop yields is larger (Tables 3, 4 and 5) at higher temperatures, but this is not the case for variability in income. Also, despite the relatively low crop yields, fnv/ha is higher and increasing faster in Mediterranean regions, which is also observed for some crop yields (Table 3 ). This suggests that farmers in regions with low crop yields adapt by decreasing input costs, changing to other crops or increase subsidized activities (as $f n v \approx$ outputs - inputs + subsidies - taxes), but also change practices to increase yields. Higher product quality or increased market value due to scarcity may also have led to higher output prices (which are observed in the FADN data). High trends are sometimes accompanied by high variability, which may be due to adaptations which can increase farmers' income in the long-term but cause more risk in the short term. Other studies mentioned hazard exposure as being an important indicator for successful adaptation (e.g., Downing et al. 2001; Smit and Skinner 2002). This seems valid for regions regularly exposed to high temperatures.

Adaptive capacity at multiple levels

Until now, many studies have quantified regional potential impacts of climate change with site-specific models. It was assumed that, by understanding these potential impacts, adaptive measures could be quantified and projections of actual impacts could be made (IPCC 2001; Metzger 2005). The actual impacts are the impacts that remain after accounting for adaptation. This study showed that although crop yield variability is larger in Mediterranean regions, this is only partly related to climate variability, and crop yield and income trends can still be high. Analyses of the direction of inter-annual yield and income variability also indicate that the impact of climate variability is not necessarily larger in the Mediterranean (Reidsma and Ewert 2008; Reidsma et al. 2008). The conclusion that Mediterranean regions are most vulnerable to climate change (e.g., Olesen and Bindi 2002; Metzger et al. 2006) needs refinement. Importantly, relationships between climate, management and farm performance are complex and potential impacts on yield and income vary not only among regions, but also among farm types within regions. Adaptation options are typically classified in autonomous and planned or proactive and reactive (Smit et al. 2001). However, explicit quantification of these adaptation types has proved difficult.

A high variability in precipitation has a negative impact on wheat and barley yields, but not on maize, sugar beet and potato yields. The latter crops are often irrigated. The area of irrigated crops has increased in most regions, as EU policies have stimulated irrigated agriculture. This may partly explain why farmers' income increases more in Mediterranean regions compared to temperate regions. However, water stress is already apparent, also in temperate regions (Alcamo and Henrichs 2002) and if water is not managed wisely, drought risks will increase (Isendahl and Schmidt 2006; Lehner et al. 2006). The short-term adaptation (or 'coping capacity') may eventually result in maladaptation on the long-term (Reilly and Schimmelpfennig 2000). 
Therefore, higher level (e.g., region or country) planned adaptation is of crucial importance for farm performance and adaptation to climate change and climate variability (Smit and Wandel 2006). Regional level adaptive capacity is related to awareness, technological and financial ability and indicators have been proposed to quantify these abilities (Smit et al. 2001; Schröter et al. 2003; Metzger et al. 2006). For the agricultural sector these indicators need to be further specified. The present study suggests that the influence of management factors may differ per farm performance measure, but that hazard exposure can stimulate adaptive responses.

\section{Conclusions}

Our analysis shows that trends and variability in climatic conditions have an impact on trends and variability in crop yields and farmers' income at region and farm type level, but that the actual impacts depend on factors influencing management. Farm types and regions adapt differently to climatic conditions, and to changes and variability herein. Results suggest that in regions with a less favorable and more variable climate (e.g., the Mediterranean) actual adaptation is higher. Although crop yield and income variability can be high, this is only partly related to climate variability, and has no negative effect on the trend in farmers' income per hectare $(f n v / h a)$ which is higher in these regions.

As climate impacts do not only vary among regions but also among farm types, concepts to explicitly quantify potential impacts and adaptive capacity appear less practical. Studies that aim to assess the impacts of climate change on agriculture need to integrate the combined effects of climate variability and change, farm characteristics and the socio-economic and policy context, and have to consider both crop yields and farmers' income as this influences the type of adaptation. Only then it will be possible to project the actual impacts of climate change on farms and regions.

Acknowledgments We thank the Netherlands Environmental Assessment Agency (MNP) for funding the PhD project of PR in which this research was carried out. We also thank the EU-funded SEAMLESS project (System for Environmental and Agricultural Modelling; Linking European Science and Society, contract no. 010036) for providing the FADN data and funding for FE. Thanks further go to the European Joint Research Centre (JRC) - Agrifish MARS STAT and Hendrik Boogaard for providing the climate data from the MARS project. We thank Bas Eickhout for providing useful comments on the paper.

Open Access This article is distributed under the terms of the Creative Commons Attribution Noncommercial License which permits any noncommercial use, distribution, and reproduction in any medium, provided the original author(s) and source are credited.

\section{References}

Adger WN, Arnell NW, Tompkins EL (2005) Adapting to climate change: perspectives across scales. Global Environ Change 15:75-76

Alcamo J, Henrichs T (2002) Critical regions: a model-based estimation of world water resources sensitive to global changes. Aquat Sci 64:352-362

Andersen, E, Verhoog, AD, Elbersen, BS, Godeschalk, FE, Koole, B (2006) A multidimensional farming system typology. SEAMLESS Report No. 12, SEAMLESS integrated project, EU 6th Framework Programme (http://www.seamless-ip.org/Reports/ Report_12_PD4.4.2.pdf)

Andersen E, Elbersen B, Godeschalk F, Verhoog D (2007) Farm management indicators and farm typologies as a basis for assessments in a changing policy environment. J Environ Manage 82:353-362

Antle JM, Capalbo SM, Elliott ET, Paustian KH (2004) Adaptation, spatial heterogeneity, and the vulnerability of agricultural systems to climate change and $\mathrm{CO}_{2}$ fertilization: an integrated assessment approach. Clim Change 64:289-315

Bakker MM, Govers G, Ewert F, Rounsevell M, Jones R (2005) Variability in regional wheat yields as a function of climate, soil and economic variables: assessing the risk of confounding. Agric Ecosyst Environ 110:195-209

Calderini DF, Slafer GA (1998) Changes in yield and yield stability in wheat during the 20th century. Field Crops Res 57:335-347

Challinor AJ, Wheeler TR, Craufurd PQ, Slingo JM, Grimes DIF (2004) Design and optimisation of a large-area process-based model for annual crops. Agric Forest Meteorol 124:99-120

Chen CC, McCarl BA, Schimmelpfennig DE (2004) Yield variability as influenced by climate: a statistical investigation. Clim Change 66:239-261

Deschenes O, Greenstone M (2006) The Economic Impacts of Climate Change: Evidence from Agricultural Profits and Random Fluctuations of Weather. Report No. 131. MIT Joint Program on the Science and Policy of Global Change. Massachusetts Institute of Technology, Cambridge

Downing TE, Harrison PA, Butterfield RE, Lonsdale KG (2000) Climate change, climatic variability and agriculture in Europe: an integrated assessment. Research Report No. 21. Environmental Change Institute. University of Oxford, Oxford. ISBN 1874370222

Downing TE, Butterfield RE, Cohen SJ, Huq S, Moss RM, Rahman A, Sokona Y, Stephen L (2001) Climate change vulnerability: linking impacts and adaptation. The Governing Council of the United nations Environment Programme (UNEP). Nairobi and Environmental Change Institute, University of Oxford, Oxford

Easterling WE, Aggarwal PK, Batima P, Brander KM, Erda L, Howden SM, Kirilenko A, Morton J, Soussana J-F, Schmidhuber J, Tubiello FN (2007) Food, fibre and forest products. In: Parry ML, Canziani OF, Palutikof JP, Linden PJVD, Hanson CE (eds) Climate change 2007: Impacts, Adaptation and Vulnerability. Contribution of Working Group II to the Fourth Assessment Report of the Intergovernmental Panel on Climate Change. Cambridge University Press, Cambridge, pp 273-313

Ewert F, Rounsevell MDA, Reginster I, Metzger MJ, Leemans R (2005) Future scenarios of European agricultural land use. I: Estimating changes in crop productivity. Agric Ecosyst Environ 107:101-116

Ewert F, Porter JR, Rounsevell MDA (2007) Crop models, $\mathrm{CO}_{2}$, and climate change. Science 315:459-460

Fischer G, Van Velthuizen H, Shah M, Nachtergaele FO (2002) Global agro-ecological assessment for agriculture in the $21 \mathrm{st}$ century: methodology and results. IIASA, Laxenburg 
Hansen JW, Jones JW (2000) Scaling-up crop models for climate variability applications. Agric Syst 65:43-72

Harrison SP, Butterfield RE, Downing T (1995) Climate change and agriculture in Europe. Assessment of impacts and adaptations. Environmental change unit. University of Oxford, Oxford

Iglesias A, Rosenzweig C, Pereira D (2000) Agricultural impacts of climate change in Spain: developing tools for a spatial analysis. Global Environ Change 10:69-80

IMAGE team (2001) The IMAGE 2.2 implementation of the SRES scenarios: A comprehensive analysis of emissions, climate change and impacts in the 21 st century. National Institute of Public Health and the Environment, Bilthoven

IPCC (2001) Climate Change 2001. Impacts, adaptation and vulnerability. Cambridge University Press, Cambridge

IPCC (2007) Climate change 2007: the physical science basis. Summary for Policymakers, Geneva

Isendahl, N, Schmidt, G (2006) Drought in the Mediterranean: WWF policy proposals. WWF-World Wide Fund for Nature

van Ittersum MK, Leffelaar PA, van Keulen H, Kropff MJ, Bastiaans L, Goudriaan J (2003) On approaches and applications of the Wageningen crop models. Eur J Agron 18:201-234

Kaufmann RK, Snell SE (1997) A biophysical model of corn yield: integrating climatic and social determinants. Am J of Agric Econ 79:178-190

Kokic P, Nelson R, Meinke H, Potgieter A, Carter J (2007) From rainfall to farm incomes-transforming advice for Australian drought policy. I. Development and testing of a bioeconomic modelling system. Australian J Agric Res 58:993-1003

Landau S, Mitchell RAC, Barnett V, Colls JJ, Craigon J, Moore KL, Payne RW (1998) Testing winter wheat simulation models' predictions against observed UK grain yields. Agric Forest Meteorol 89:85-99

Lehner B, Droll P, Alcamo J, Henrichs T, Kaspar F (2006) Estimating the impact of global change on flood and drought risks in Europe: a continental, integrated analysis. Clim Change 75: 273-299

Lobell DB, Asner GP (2003) Climate and management contributions to recent trends in U.S. agricultural yields. Science 299:1032

Lobell DB, Ortiz-Monasterio JI, Asner GP, Matson PA, Naylor RL, Falcon WP (2005) Analysis of wheat yield and climatic trends in Mexico. Field Crops Res 94:250-256

Marshall B, Crawford JW, Porter JR (1997) Variability and scaling: matching methods to mechanisms. In: van Gardingen PR, Foody GM, Curran PJ (eds) Scaling-up: from cell to landscape. Cambridge University Press, Cambridge, pp 253-272

van Meijl H, van Rheenen T, Tabeau A, Eickhout B (2006) The impact of different policy environments on agricultural land use in Europe. Agric Ecosyst Environ 114:21-38

Mendelsohn R (2007) Measuring climate impacts with cross-sectional analysis. Clim Change 81:1-7

Mendelsohn R, Nordhaus WD, Shaw D (1994) The impact of global warming on agriculture-a Ricardian analysis. Am Econ Rev 84:753-771

Metzger, MJ (2005) European vulnerability to global change. A spatially explicit and quantitative assessment. $\mathrm{PhD}$ thesis. Wageningen University, Wageningen

Metzger MJ, Rounsevell MDA, Acosta-Michlik L, Leemans R, Schroter D (2006) The vulnerability of ecosystem services to land use change. Agric Ecosyst Environ 114:69-85

O'Brien K, Sygna L, Haugen JE (2004) Vulnerable or resilient? A multi-scale assessment of climate impacts and vulnerability in Norway. Clim Change 64:193-225

Olesen JE, Bindi M (2002) Consequences of climate change for European agricultural productivity, land use and policy. Eur $\mathrm{J}$ Agron 16:239-262
Parry ML, Rosenzweig C, Iglesias A, Livermore M, Fischer G (2004) Effects of climate change on global food production under SRES emissions and socio-economic scenarios. Global Environ Change 14:53-67

Passioura JB (1996) Simulation models: science, snake oil, education, or engineering? Agron J 88:690-694

Potgieter AB, Hammer GL, Doherty A, De Voil P (2005) A simple regional-scale model for forecasting sorghum yield across NorthEastern Australia. Agric Forest Meteorol 132:143-153

Reidsma, P, Ewert, F (2008) Regional farm diversity can reduce vulnerability of food production to climate change. Ecology and Society 13(1):38. http://www.ecologyandsociety.org/vol13/iss1/ art38/

Reidsma P, Ewert F, Oude Lansink A (2007) Analysis of farm performance in Europe under different climate and management conditions to improve understanding of adaptive capacity. Clim Change 84:403-422

Reidsma, P, Oude Lansink, A, Ewert, F (2008) Economic impacts and observed adaptation strategies to climate variability and subsidies in European agriculture. Mitig Adapt Strat Glob Change. doi:10.1007/s11027-008-9149-2

Reilly J (2002) Agriculture: the potential consequences of Climate Variability and Change for the United States. University Press, Cambridge

Reilly J, Schimmelpfennig D (2000) Irreversibility, uncertainty, and learning: Portraits of adaptation to long-term climate change. Clim Change 45:253-278

Saarikko RA (2000) Applying a site based crop model to estimate regional yields under current and changed climates. Ecol Model 131:191-206

Schröter D, Acosta-Michlik L, Reidsma P, Metzger M, Klein RJT (2003) Modelling the vulnerability of eco-social systems to global change: Human adaptive capacity to changes in ecosystem service provision. Paper presented at the Fifth Open meeting on the Human Dimensions of Global Change, Montreal, 16-18 October 2003

Smit B, Skinner M (2002) Adaptation options in agriculture to climate change: a typology. Mitig Adapt Strat Glob Change 7:85-114

Smit B, Wandel J (2006) Adaptation, adaptive capacity and vulnerability. Global Environ Change 16:282-292

Smit B, Pilifosova OV, Burton I, Challenger B, Huq S, Klein RJT, Yohe G, Adger N, Downing T, Harvey E, Kane S, Parry ML, Skinner M, Smith J, Wandel J (2001) Adaptation to climate change in the context of sustainable development and equity. In: McCarthy JJ, Canziani OF, Leary NA, Dokken DJ, White KS (eds) Climate change 2001. Impacts, adaptation, and vulnerability. Cambridge University Press, Cambridge, pp 876-912

Snijders TAB, Bosker RJ (1999) Multilevel analysis: an introduction to basic and advanced multilevel modeling. Sage, New York

Tao F, Yokozawa M, Xu Y, Hayashi Y, Zhang Z (2006) Climate changes and trends in phenology and yields of field crops in China, 1981-2000. Agric Forest Meteorol 138:82-92

Thorhallsdottir TE (1990) The dynamics of a grassland community: a simultaneous investigation of spatial and temporal heterogeneity at various scales. J Ecol 78:884-908

Trnka M, Dubrovsky M, Zalud Z (2004) Climate change impacts and adaptation strategies in spring barley production in the Czech Republic. Clim Change 64:227-255

Tubiello FN, Ewert F (2002) Simulating the effects of elevated $\mathrm{CO}_{2}$ on crops: approaches and applications for climate change. Eur J Agron 18:57-74

Tubiello FN, Donatelli M, Rosenzweig C, Stockle CO (2000) Effects of climate change and elevated $\mathrm{CO} 2$ on cropping systems: model predictions at two Italian locations. Eur J Agron 13:179-189 